\title{
Common and Uncommon Presentation of Fluid within the Scrotal Spaces
}

\author{
Authors \\ V. Patil, S. M. C. Shetty, S. Das \\ Affiliation \\ Radiodiagnosis, JSS Medical College, Mysore, India
}

Key words
US
ultrasonography
fluid
testis
scrotum

received 21.01.2015 accepted $\quad 29.06 .2015$

\section{Bibliography}

DOI http://dx.doi.org/

10.1055/s-0035-1555919

Published online:

November 6, 2015

Ultrasound International Open

2015; 1: E34-E40

(c) Georg Thieme Verlag KG

Stuttgart · New York

ISSN 2199-7152

\section{Correspondence}

\section{Dr. Vikram Patil}

Radiodiagnosis

JSS Medical College

101, Gayathri Apartment

New Kantharj Urs Road, Mysore

570004, Mysore

India

Tel.: + 91/988/6896 511

drvikrampatil@yahoo.com

\section{License terms}

\section{Abstract}

$\checkmark$

Ultrasonography(US) of the scrotum has been demonstrated to be useful in the diagnosis of fluid in the scrotal sac. Grayscale US characterizes the lesions as testicular or extratesticular and, with color Doppler, power Doppler and pulse Doppler, any perfusion can also be assessed. Cystic or encapsulated fluid collections are relatively common benign lesions that usually present as palpable testicular lumps. Most cysts arise in the epidydimis, but all anatomical structures of the scrotum can be the site of their ori-

\section{Introduction}

Scrotal conditions associated with fluid can be broadly classified as fluid in scrotal sac, testicular cysts, epididymal cysts and inguinoscrotal hernia.

\section{Examination Technique}

Scrotal US is performed with the patient in the supine position and the scrotum supported by a towel placed between the thighs. Optimal results are obtained with a high-frequency linear array transducer above $10 \mathrm{MHz}$. Scanning is performed most often with the transducer in direct contact with the skin, but if necessary a stand-off pad can be used for evaluation of superficial lesions. The testes are examined in at least 2 planes along the long and transverse axes. The size and echogenicity of each testis and the epididymis are compared with those on the opposite side. Scrotal skin thickness is evaluated. Scrotal skin echogenicity is also evaluated.

In patients being evaluated for an acute scrotum, the asymptomatic side should be scanned initially in order to set the gain settings to allow comparison with the affected side. Transverse gin. US may suggest a specific diagnosis for a wide variety of intrascrotal cystic and fluid lesions and appropriately guide therapeutic options. The paper reviews the current knowledge of ultrasound in conditions with fluid in the testis and scrotum. The review presents the applications of ultrasonography in the diagnosis of hydrocele, testicular cysts, epididymal cysts, spermatoceles, tubular ectasia, hernia and hematoceles. The aim of this paper is to provide a pictorial review of the common and uncommon presentation of fluid within the scrotal spaces. images with portions of each testis on the same image should be ideally acquired in grayscale and color Doppler modes. The structures within the scrotal sac are examined to detect extra testicular masses or other abnormalities. In patients with small palpable nodules, scans should include the area of clinical concern. It is helpful to put a finger beneath the nodule and the transducer placed directly over the nodule for scanning, or a finger can be placed on the nodule and the transducer opposite to confirm imaging of the lesion.

\section{Sonographic Anatomy of Scrotum \\ $\nabla$}

The normal adult testis is ovoid, measuring $3-5 \mathrm{~cm}$ in length and $2-3 \mathrm{~cm}$ in both transverse and anteroposterior dimensions. Its echo texture is homogeneous, and its echogenicity is intermediate.

The epididymal head is rhomboid to triangular in shape, measures less than $1 \mathrm{~cm}$, and is similar in echo texture and echogenicity to the testis. The epididymal head is positioned superolaterally to the testis with the body of the epididymis aligned along the long axis posteriorly. Occasionally, testicular appendages such as the appendix testis, a 
Table 1 Cystic/liquid lesions of the scrotum in adults.

1. Fluid in scrotal sac
a. Congenital hydrocele
b. Spermatic cord hydrocele
c. Acquired hydrocele
d. Hematocele
e. Pyocele
f. Lymphocele
2. Testicular lesions
a. Tunica albuginea cysts
b. Single or multiple cysts
c. Tubular ectasia
d. Epidermoid cysts
e Testicular abscess
f. Intratesticular varicocele
g. Post-traumatic cysts
3. Cysts in the epididymis
a. Epididymal cysts
b. Spermatocele
c. Tubular ectasia of the epididymis
d. Cyst of the appendix testis and appendix epididymis
4. Inguinoscrotal hernia

mullerian duct remnant found at the superior aspect of the testis, and the appendix epididymis, a mesonephric remnant located at the epididymal head, can also be seen.

The appendix testis appears as an ovoid structure $5 \mathrm{~mm}$ in length in the groove between the testis and the epididymis. The appendix testis is isoechoic to the testis and may occasionally be cystic. The appendix epididymis is of the same approximate dimensions as the appendix testis but is more often pedunculated [1]. Normal structures of the scrotal canal (veins, artery) can also be identified ( $\bullet$ Table 1 ).

\section{Fluid in Scrotal Sac \\ $\nabla$}

\section{Hydrocele}

Hydrocele is an abnormal collection of fluid between the visceral and parietal layers of the tunica vaginalis and/or along the spermatic cord. In the normal scrotum, $1-2 \mathrm{~mL}$ of serous fluid may be observed in the potential tunica vaginalis cavity and should not be mistaken for hydrocele.

It may be congenital or acquired (primary/idiopathic and secondary).

Hydrocele is the most common cause of painless scrotal swelling in children. Virtually all hydroceles are congenital in neonates and infants and associated with a patent processus vaginalis, which allows peritoneal fluid to enter the scrotal sac [2]. In older children and adolescents, hydroceles are usually acquired and are the result of an inflammatory process, testicular torsion, trauma, or a tumor.

At sonography, congenital hydrocele appears as an anechoic fluid collection surrounding the anterolateral aspects of the testis and sometimes extending to the inguinal canal or as a fluid collection with low-level swirling echoes, which are related to protein aggregation or deposition of cholesterol crystals [2] $(\bullet$ Fig. 1,2).

Closure of the processus vaginalis above the testis and below the internal inguinal ring leads to a less common type of hydrocele, also known as spermatic cord hydrocele, which appears as a fluid collection in the spermatic cord [2]. Another type, referred to as abdominoscrotal hydrocele, is a highly uncommon entity,

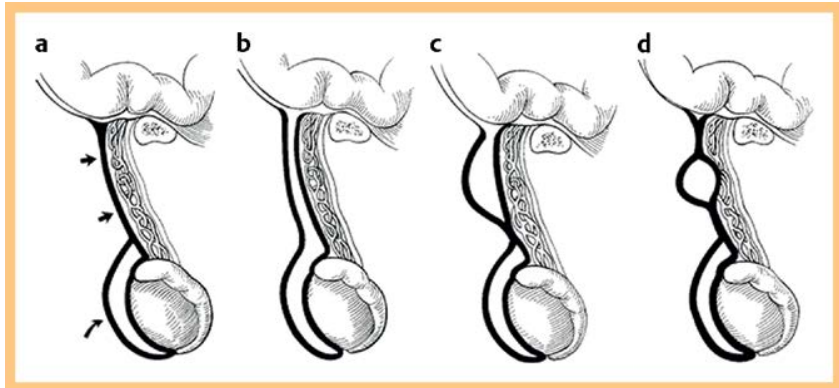

Fig. 1 a Normal closure of processus vaginalis. Straight arrows indicate funicular process and curved arrow indicates tunica vaginalis. b Communicating hydrocele - complete patency of tunica vaginalis. c Funicular hydrocele of the cord - diverticulum communicates with the cord only. d Encysted hydrocele of the cord - no communication to peritoneum or tunica vaginalis.

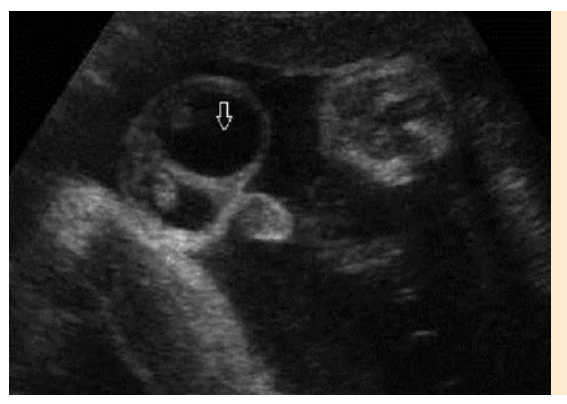

Fig. 2 Antenatal hydrocele shows the fluid in the scrotal sac with echogenic testis.

with only about 80 reported pediatric cases [3]. These are large inguinoscrotal hydroceles that protrude through the internal inguinal ring into the abdominal cavity and manifest clinically as a communicating abdominal-scrotal mass. The exact mechanism by which peritoneal fluid is forced into the abdominal cavity remains speculative [4].

Most congenital hydroceles (80\%) resolve spontaneously before the age of 2 years. However, surgical treatment is usually applied in spermatic cord and abdominoscrotal hydroceles.

\section{Spermatic cord hydrocele}

Hydrocele of the spermatic cord is a rare anomaly that results from an aberration in the closure of the processus vaginalis. It is a loculated fluid collection along the spermatic cord, separate from the testis and the epididymis and located above them. Clinically it manifests as groin swelling that is indistinguishable from a mass at palpation.

There are 3 types of spermatic cord hydrocele: communicating, funicular, and encysted. A communicating hydrocele is associated with complete patency of the processus vaginalis. On US, it appears as a fluid collection that extends from the pelvis through the deep inguinal ring to the scrotum. A funicular hydrocele is a result of abnormal obliteration of the deep inguinal ring, with constriction just above the testis. On US, it resembles a peritoneal diverticulum, appearing as a fluid collection that communicates with the peritoneum at the deep inguinal ring and that does not surround the testicle [5]. A funicular hydrocele may contain fibrous adhesions, the remnants of partial constrictions and inflammatory changes. The resultant beaded appearance of the spermatic cord and thickened tunica vaginalis gave rise to the term pachyvaginalitis. Funicular hydroceles become larger with increased intraperitoneal pressure during straining and smaller during relaxation [6]. They are prevalent in children and premature infants. However, they may be incidentally discov- 


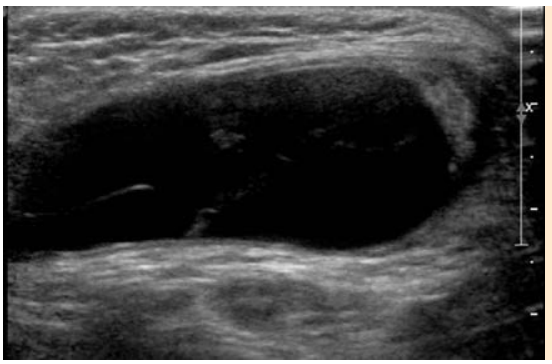

Fig. 3 An ovoid anechoic mass is seen in the groin along the spermatic cord - spermatic cord hydrocele.

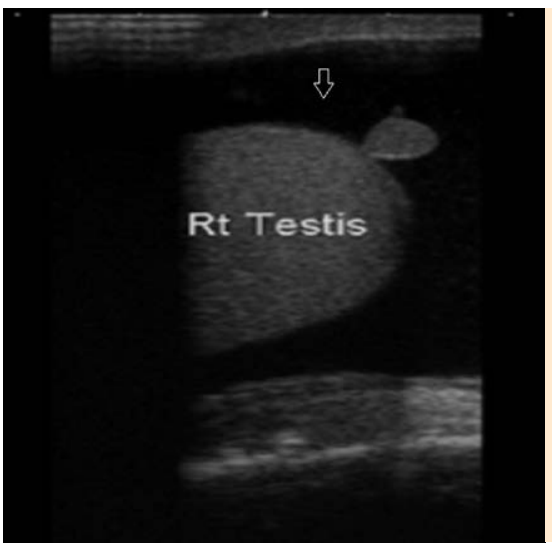

Fig. 4 Hydrocele noted with testicular appendage is well defined.

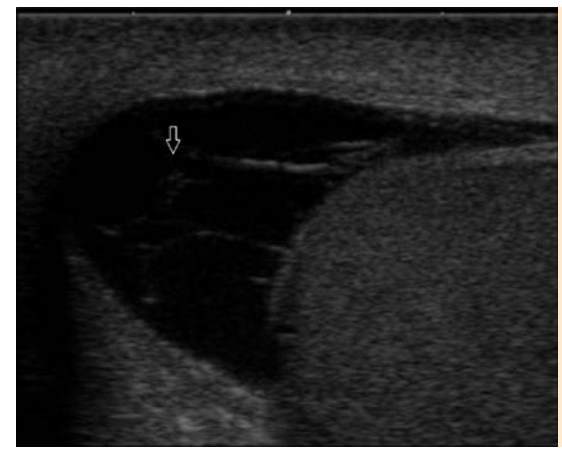

Fig. 5 Chronic hydrocele showing fluid having multiple thin septations in the scrotal sac.

ered in adults. They are considered a type of potential indirect hernia, and herniotomy is usually performed. An encysted hydrocele is enclosed between 2 constrictions at the deep inguinal ring, just above the testis. It does not communicate with the peritoneum. An encysted hydrocele may be located anywhere along the spermatic cord. It may be any size or shape, but it does not change with increased peritoneal pressure. On US, an ovoid or round mass is seen in the groin along the spermatic cord. Internal echogenicity varies depending on the contents ( $\bullet$ Fig. 3). The presence of cholesterol deposits may explain an isoechoic appearance of the mass.

\section{Acquired hydrocele}

A minimal amount of fluid is normally present between the parietal and visceral layers of the tunica vaginalis. An abnormal amount of fluid between the 2 layers surrounding the testis is called a hydrocele, the most common cause of scrotal enlargement. Acquired hydrocele may form as a reaction to tumor, infection, or trauma. It also may be idiopathic, resulting from excessive fluid production or failure of the mesothelial lining to reabsorb the fluid. On US, anechoic fluid collection is seen surrounding the testis ( $\bullet$ Fig. 4 ). The collection may contain septa ( $\odot$ Fig. 5), calculi, and scattered echoes caused by protein or cholesterol content [5]. A massive hydrocele exerts a pressure effect mimicking that in testicular torsion and may compromise blood

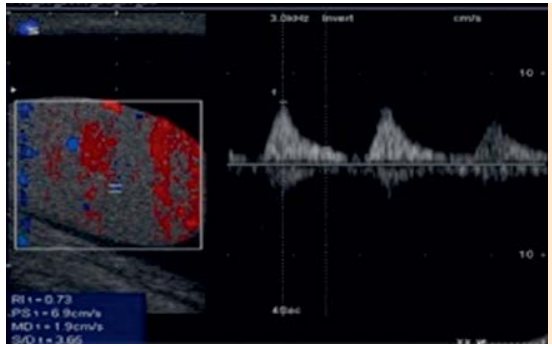

Fig. 6 An increase in the resistive index (RI) of the testicular artery is seen due to a compressive effect on the vessels.

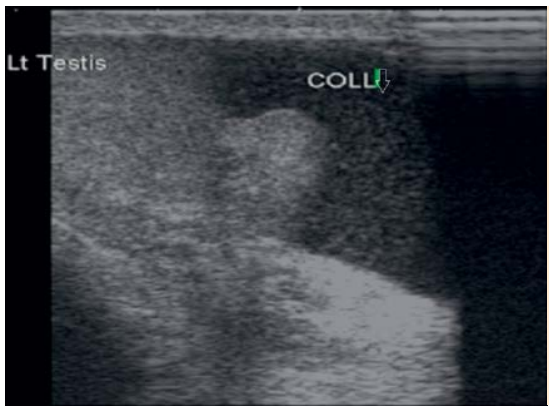

Fig. 7 Low-level echoes seen in the scrotal fluid collection indicative of hematocele.

flow within the testis. Vascular resistance in intratesticular arteries is increased ( $\bullet$ Fig. 6 ), and color Doppler US may demonstrate an increase in the caliber of capsular arteries [8]. Aspiration of the fluid restores normal blood flow to the testis. In patients with hydrocele, the volume of the homolateral testis is increased and so are the RI and the pulsatility index (PI). Postoperatively, both the volume and impedance indices decrease.

\section{Hematocele}

In most of the patients, the injury will be solitary but may be associated with involvement of the penis or urethra. The right side is involved more often than the left side. As the left testis is more dependent, the mobility of the testicle, cremasteric muscle contraction and the tough capsule (tunica albuginea) usually protect it from injury. However a direct blow that drives the testicle against the symphysis pubis may result in contusion or rupture. Rupture is usually accompanied by hematocele formation and scrotal wall ecchymosis. The hematocele may be minimal to moderate because the extruded testicular tissue and bleeding are limited by tunica vaginalis. If on the other hand, tunica vasculosa is involved, the hematocele may be large and compress the testicular parenchyma, eventually leading to parenchymal atrophy if untreated. It may be acute or chronic.

Acute hematocele: In the hyper acute stage, the hematocele if containing unclotted liquid blood appears as an anechoic fluid collection bounded by the tunical sac. With high gain settings, low-level echoes may be seen ( $\bullet$ Fig. 7). With clotting of blood in the tunical sac, hyperechoic areas are noted within the tunical sac, representing the blood clot. With further progression of time, clot lysis occurs and hyperechoic areas progressively reduce in size and number [9].

Chronic hematocele: The US features are anechoic fluid collection with multiple septations in the tunical sac. An increase in the size of the hematocele in comparison to the acute stage is seen in some patients. Reduction in testicular size and compressed testes may also be noted.

Over time, its appearance becomes more complex, with septa, fluid-fluid levels, and echogenic debris indicative of clots. If a hematocele becomes chronic, it may appear as a heterogeneous 
encapsulated lesion that may calcify and create a mass effect over the contour of the testis. Doppler US/CEUS can help in the differentiation of chronic hematoceles that can mimic a solid mass. Most hematoceles resolve with conservative therapy, although chronic complex hematoceles may require surgical management [10].

Lymphocele: This condition occurs in post-renal transplant patients \& elephantiasis. Lymphocele of the scrotal sac is believed to occur due to obstruction of scrotal lymphatics or due to dissection of peritransplant lymphatics. On high-frequency US, the lymphocele appears as an anechoic fluid collection with multiple septations. Low-level echoes are noted with higher gain settings. A lymphocele cannot be differentiated from a septated hydrocele or liquefying hematocele based on imaging findings alone.

\section{Pyocele and scrotal abscess}

A pyocele may occur as a complication of trauma, surgery, or epididymo-orchitis when the mesothelial lining of the tunica vaginalis is breached and infection ensues. Clinical history and physical examination of a painful scrotum help in making the diagnosis. On US, a pyocele often appears as a septate or complex heterogeneous fluid collection. A pyocele organized as an abscess has a well-defined hyperemic wall. Gas bubbles within the fluid collection appear as hyperechoic foci with "dirty shadowing" ( $\bullet$ Fig. 8). In most cases, conservative treatment with antibiotics is sufficient. However, a scrotal abscess complicated by necrotizing infection of the perineum requires surgical debridement [11].

\section{Testicular Cysts}

$\nabla$

Cysts of the tunica albuginea: The etiology of cysts of the tunica albuginea is unknown, but these cysts are believed to be mesothelial in origin. Recent reports suggest an incidence of $5-10 \%$ in the general population. Tunica albuginea cysts lie outside the parenchyma of testis on the surface. They are thought to be either dilated blind ending efferent tubules or mullerian/ mesonephric duct remnants. They may also occur secondary to inflammation or trauma.

The cysts commonly range from $2-5 \mathrm{~mm}$ in size, are located peripherally and are often detected only when a patient presents with a palpable mass [12]. They can be unilocular or multilocular. On high-frequency US they appear as simple cysts with smooth contours, a thin wall, anechoic contents and posterior acoustic enhancement proportional to cyst size. They sometimes calcify, and all that remains is the palpable calcification, which casts an acoustic shadow.

Simple cysts: Usually detected incidentally and most often occurring in men at least 40 years of age, simple cysts mainly vary in size from $2 \mathrm{~mm}$ to $2 \mathrm{~cm}$. These cysts are usually solitary but can also be multiple. They are usually located adjacent to the mediastinum testis and are associated with extratesticular spermatoceles. On US, they appear with an anechoic center and through-transmission and without a perceptible wall [13] (० Fig. 9). Suspected causes of intratesticular cysts include trauma, surgery, and prior inflammation. They do not require treatment. Complicated cysts show irregular borders, a thick wall, mural nodule, calcification, suggesting the possibility of malignancy.

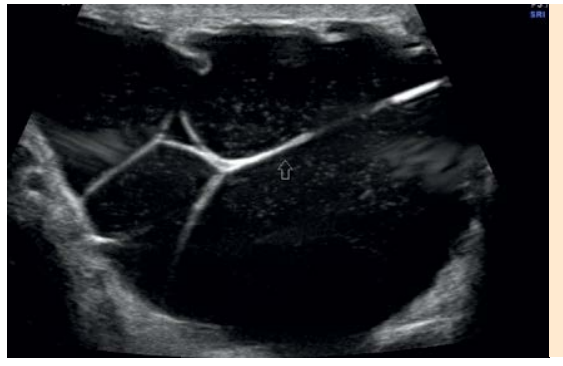

Fig. 8 A pyocele appearing as a septated fluid collection with complex heterogeneous fluid.

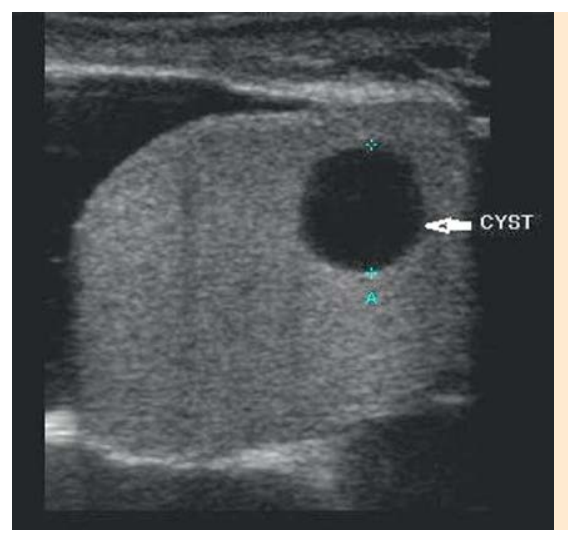

Fig. 9 Simple cyst showing an intratesticular anechoic center and throughtransmission without a perceptible wall.

Epidermoid cyst: Commonly ranging in size from 1 to $3 \mathrm{~cm}$, epidermoid cysts are uncommon benign tumors of germ cell origin and are also known as keratocysts. They are nontender and may be palpable. The patient's age at presentation is variable but commonly ranges from 20 to 40 years [14]. The US appearance of epidermoid cyst varies with the maturation, compactness, and quantity of keratin within the cyst. 4 US appearances have been described: (a) a target appearance - a halo with a central area of increased echogenicity, (b) a sharply defined mass with a rim of calcification, (c) a solid mass with an echogenic rim, and (d) the classic appearance of an "onion-ring" pattern with alternating hyperechoic and hypoechoic layers. This onion-ring pattern is considered characteristic of an epidermoid cyst and corresponds to its natural evolution $[15,16]$. Color flow or pulsed Doppler US examination demonstrates no blood flow within the cyst. The combination of an onion-ring configuration, negative tumormarker status, and avascularity in the lesion help to differentiate a testicular epidermoid cyst from other germ cell tumors [17]. Care of these patients is based on results of total urologic evaluation followed by excisional biopsy findings that provide the final diagnosis and guide management.

Tubular ectasia of rete testis: Tubular ectasia of the rete testis is a benign condition resulting from partial or complete obliteration of the efferent ducts that cause ectasia of the rete testis. The US appearance is of fluid-filled tubular structures. Tubular ectasia occurs in men older than 55 years and is frequently bilateral. Findings of cystic dilatation in or adjacent to the mediastinum testis and the presence of epididymal cysts are characteristics of tubular ectasia and aid in distinguishing it from malignant cystic testicular tumors, which can occur anywhere in the testicular parenchyma [18].

On US examination, ectasia of the rete testis can present a different appearance according to the progress of the process which can sometimes be limited to a few dilated tubules near the testicular hilum or appear as a network of small cysts occupying 


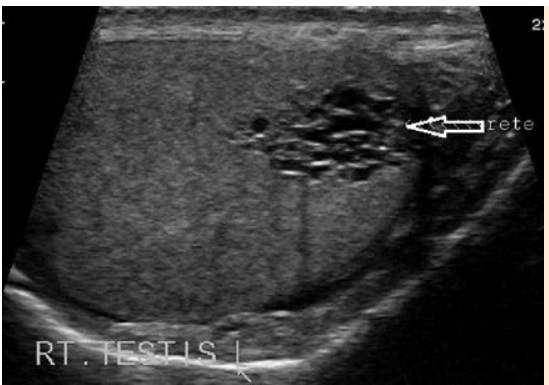

Fig. 10 Cystic dilatation adjacent to the mediastinum testis indicative of tubular ectasia of rete testis.

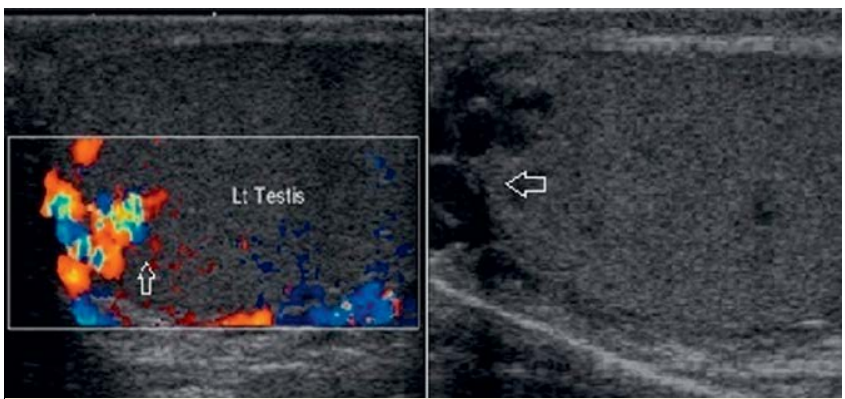

Fig. 11 Multiple anechoic, serpiginous, tubular structures of varying sizes. Color Doppler US demonstrates the venous flow pattern that increases during a Valsalva maneuver.

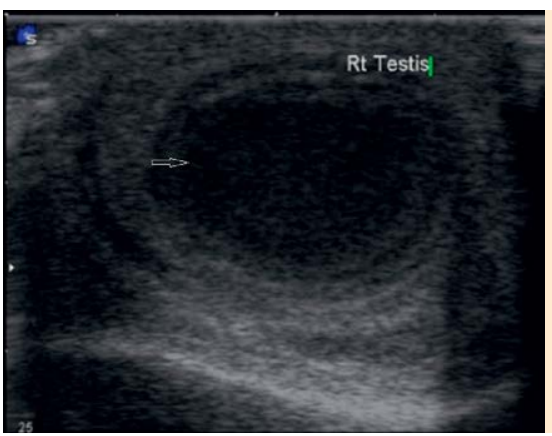

Fig. 12 Shaggy irregular walls noted in an intratesticular lesion that shows low-level internal echoes.

the central portion of the testis ( $\odot$ Fig. 10). Although ectasia of the rete testis is a benign lesion, it may cause oligospermia and azoospermia and consequent infertility [7].

Differential diagnosis should include both cystic dysplasia of the rete testis, which is most often seen in children and associated with urinary tract malformations, and intratesticular varicose veins of the testicles which are easily diagnosed using color Doppler US.

Intratesticular varicocele: The pathogenesis and clinical implications of the newly defined condition intratesticular varicocele are not yet well established. An intratesticular varicocele can occur in association with an extratesticular varicocele, but intratesticular varicoceles are more commonly found alone [19]. Patients with intratesticular varicocele may have pain related to passive congestion of the testis, which eventually stretches the tunica albuginea. The US appearance of an intratesticular varicocele is similar to that of an extratesticular varicocele.

The dilated veins are usually seen predominantly in the mediastinum testis, but substantial enlargement of parenchymal veins is seen in one third of the reported cases. In addition to these 2 main topographies (hilar and testicular), prominent dilatation of subcapsular veins are also reported in some cases [33]. Intratesticular varicocele US features include multiple anechoic, serpiginous, tubular structures of varying sizes ( $\bullet$ Fig. 11). Color

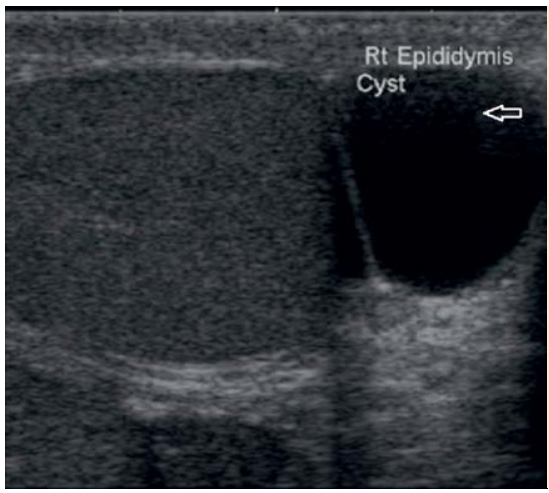

Fig. 13 Well defined cyst in the head of epididymis in a case of epididymal cyst.

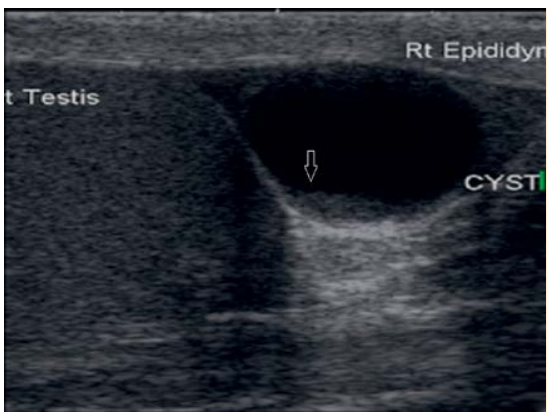

Fig. 14 Cystic lesion in the epididymal head that contains internal echoes showing a fluidfluid level.

flow and duplex Doppler US demonstrate the venous flow pattern with a characteristic venous spectral waveform that increases during a Valsalva maneuver.

Intratesticular abscess: An abscess is usually secondary to epididymo-orchitis, but other causes of intratesticular abscess include mumps, trauma, and testicular infarction. The US features include shaggy irregular walls, intratesticular location, low-level internal echoes ( $\bullet$ Fig. 12), and, occasionally, hypervascular margins with color Doppler [20].

\section{Epididymal Cysts}

Epididymal cyst: They occur in approximately $30 \%$ of the general population. They are typically small and unilocular. Most arise in the epididymal head, although they can occur in the body and tail ( $\bullet$ Fig. 13). Epididymal cysts may be observed in association with tubular ectasia of the rete testis. Both lesions fulfill sonographic criteria for cysts, appearing anechoic. It is difficult to distinguish between cysts and spermatoceles on US. CEUS can help in the differentiation between an epidermoid cyst and a solid mass.

Spermatocele: This is a retention cyst arising from some portion of sperm conducting tubules of the epididymis. It is usually situated in the epididymal head and hence is above and behind the testis. Spermatoceles tend to be larger and multiloculated and are also located predominantly in the region of the epididymal head. The typical sonographic appearance of a spermatocele is a unilocular or oligolocular thin-walled hypoechoic structure of variable size within the epididymal head that displaces the ipsilateral testis [24-26]. Classically, it contains internal echoes. It should be noted that internal echoes within a cystic lesion in the epididymis may represent debris from another process, such as an infection or a hematoma. Large spermatoceles tend to dis- 


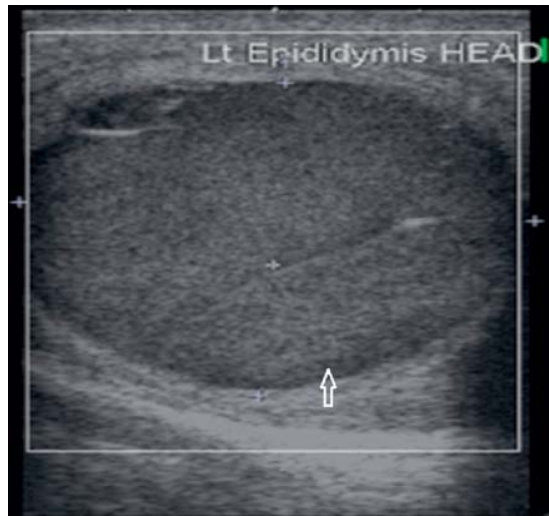

Fig. 15 Large lesion in the head of epididymis with internal echoes within a cystic lesion with no vascularity within mimicking a mass lesion.

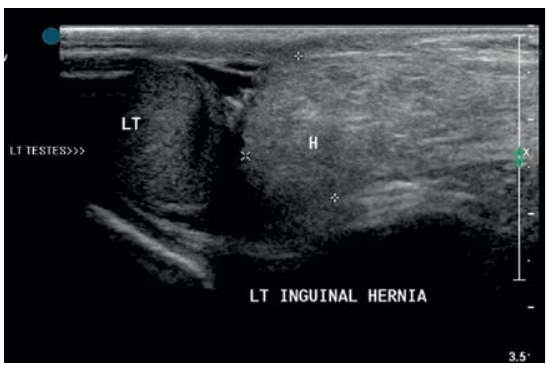

Fig. 16 Identification of loops of bowel noted within the scrotum with minimal fluid around it in inguinoscrotal hernia.

place the testis anteriorly and may be septated. Spermatoceles may show evidence of fluid-fluid levels [21-23] ( $\bullet$ Fig. 14). The combination of a history, a physical examination, and characteristic sonographic findings is usually sufficient to diagnose a spermatocele ( $\bullet$ Fig. 15).

Cyst of the appendix testis and appendix epididymis

The appendices of the testis and epididymis are residual cells from the ducts of Muller or mesonephric duct tissue. They are commonly found at autopsy [27], although US examination reveals their presence in only $6-17 \%$ of patients [28]. They are clinically insignificant but may undergo torsion thereby causing intense pain that may prompt the patient to seek medical care and diagnostic investigation. Cysts of the appendix of testis (Hydatid of Morgagni) rarely present a cystic internal structure [29], but cysts of the head of the epididymis are usually cystic as they arise from residues of congenital tubular dilations [30]. After torsion of the pedicle, they can fall into the vaginal space and appear as small mobile cysts. They are easily identified in the presence of hydrocele [31].

\section{Inguino-Scrotal Hernia}

Inguino-scrotal hernias are classified into direct and indirect types. An indirect hernia leaves the abdominal cavity at the internal ring, traverses through the inguinal canal, and if complete - extends up to the inferior aspect of scrotal sac. A direct hernia protrudes forward through the Hesselbach's triangle and may extend into the scrotum via a superficial ring. Diagnosis is made based on history and careful clinical examination. Occasionally scrotal hernias may present as firm non-transluminent, non-reducible masses mimicking primary scrotal pathology.

The sonographic criteria to reliably differentiate scrotal hernia from primary scrotal pathology are: Identification of loops of bowel within the scrotum, exclusion of testicular pathology by demonstrating normal testicular elements, presence of hernial sac in the inguinal region containing bowel and/or omentumcontinuation of hernia sac from inguinal canal to scrotum.
On US, intestinal loops within the scrotum appear as tubular structures containing hyperechoic air bubbles or fluid. Peristalsis of bowel loops is easily detected because of the movement of gas bubbles ( $\bullet$ Fig. 16). The herniated omentum appears as a highly echogenic structure [32].

Hernias that contain omentum may be more difficult to diagnose because their appearance is similar to that of lipomas. However, whereas a lipoma appears as a well-defined or encapsulated mass, a herniated omentum is more elongated, and branching omental vessels are easily identified on color Doppler US.

\section{References}

1 Hricak H, Filly RA. Sonography of the scrotum. Invest Radiol 1983; 18: $112-121$

2 Gooding GA, Leonhardt WC, Marshall G et al. Cholesterol crystals in hydroceles: sonographic detection and possible significance. AJR Am J Roentgenol 1997; 169: 527-529

3 Avolio L, Chiari G, Caputo MA et al. Abdominoscrotal hydrocele in childhood: is it really a rare entity? Urology 2000; 56: 1047-1049

4 Ferro F, Lais A, Cinzia $O$ et al. Abdominoscrotal hydrocele in childhood. Pediatr Surg Int 1995; 10: 276-278

5 Martin LC, Share JC, Peters C et al. Hydrocele of the spermatic cord: embryology and ultrasonographic appearance. Pediatr Radiol 1996; 26: $528-530$

6 Rathaus $V$, Konen $O$, Shapiro $M$ et al. Ultrasound features of spermatic cord hydrocele in children. Br J Radiol 2001; 74: 818-820

7 Rouvière 0 , Bouvier R, Pangaud C et al. Tubular ectasia of the rete testis: a potential pitfall in scrotal imaging. Eur Radiol 1999; 9: 1862-1868

8 Mihmanli I, Kantarci F, Kulaksizoglu $H$ et al. Testicular size and vascular resistance before and after hydrocelectomy. AJR Am J Roentgenol 2004; 183: 1379-1385

9 Harding Rains AJ, David Ritchie H (Eds.). Bailey and Loves Short practice of Surgery. $19^{\text {th }}$ Ed. London: ELBS; 1981: 1253-1275

10 Fournier GR et al. Scrotal Ultrasonography and the Management of Testicular Trauma. Urologic Clinics of North America 1989; 16: 377-385

11 Aso C, Enríquez G, Fité $M$ et al. Gray-scale and color Doppler sonography of scrotal disorders in children: an update. RadioGraphics 2005; 25: $1197-1214$

12 Martinez-Berganza MT, Sarria L, Cozcolluela R et al. Cysts of the tunica albuginea: sonographic appearance. AJR Am J Roentgenol 1998; 170: 183-185

13 Gooding GA, Leonhardt W, Stein R. Testicular cysts: US findings. Radiology 1987; 163: 537-538

14 Shah KH, Maxted WC, Chun B. Epidermoid cysts of the testis: a report of three cases and an analysis of 141 cases from the world literature. Cancer 1981; 47: 577-582

15 Langer JE, Ramchandani P, Siegelman ES et al. Epidermoid cysts of the testicle: sonographic and MR imaging features. AJR Am J Roentgenol 1999; 173: 1295-1299

16 Dogra VS, Gottlieb RH, Rubens DJ et al. Testicular epidermoid cysts: sonographic features with histopathologic correlation. J Clin Ultrasound 2001; 29: 192-196

17 Bree RL, Hoang DT. Scrotal ultrasound. Radiol Clin North Am 1996; 34: $1183-1205$

18 Yalowitz BR, Eble JN, Wilks DC. Spermatozoa-containing simple cysts of the retetestis. J Urol 1989; 142: 1572-1573

19 Das KM, Prasad K, Szmigielski Wet al. Intratesticular varicocele: evaluation using conventional and Doppler sonography. AJR Am J Roentgenol 1999; 173: 1079-1083

20 Dogra VS, Gottlieb RH, Rubens DJ et al. Benign intratesticular cystic lesions: US features. RadioGraphics 2001; 21: S273-S281

21 Leung ML, Gooding GA, Williams RD et al. High-resolution sonography of scrotal contents in asymptomatic Subjects. AJR 1984; 143: 161-164

22 Rifkin MD. ultrasonography of Epididymis. Radiology 1984; 151: 187-190

23 Hamm B, Fobbe F, Loy $V$ et al. Testicular cysts: differentiation with US and Clinical findings. Radiology 1988; 168: 19-23

$24 \mathrm{Hamm}$ B. Differential diagnosis of scrotal masses by ultrasound. Eur Radiol 1997; 7: 668-679

25 Hricak H, Filly RA. Sonography of the scrotum. Invest Radiol 1983; 18: $112-121$

26 Rifkin MD, Kurtz AB, Goldberg BB. Epididymis examined by ultrasound: correlation with pathology. Radiology 1984; 151: 187-190 
27 Rolnick D, Kawanoue S, Szanto P et al. Anatomical incidence of testicular appendages. J Urol 1968; 100: 755-756

28 Dogra VS, Gottlieb RH, Oka M et al. Sonography of the scrotum. Radiology 2003; 227: 18-36

29 Sahni D, Jit I, Joshi $K$ et al. Incidence and structure of the appendices of the testis and epididymis. J Anat 1996; 189: 341-348

30 Kantarci $F$, Ozer H, Adaletli I et al. Cystic appendix epididymis: a sonomorphologic study. Surg Radiol Anat 2005; 27: 557-561
31 Johnson KA, Dewbury KC. Ultrasound imaging of the appendixtestis and appendix epididymis. Clin Radiol 1996; 51: 335-337

32 Subramanyam BR et al. Sonographic diagnosis of Scrotal Hernia. AJR 1982; 139: 535-538

33 Atasoy C, Fitoz S. Gray-scale and color Doppler sonographic findings in intratesticular varicocele. J Clin Ultrasound 2001; 29: 369-373 